might give prolonged freedom from purulent relapse. Our findings suggest that penicillin and streptomycin given in high dosage reach sputum concentrations (Zinnemann, 1960 ; Hafez et al., 1965) sufficient to overcome the majority of strains of $H$. influenzae (Turk and May, 1967). Similar findings both in laboratory assays and in patients have been described by Mulder et al. (1952) and by Goslings et al. (1961).

These are overall results and indicate the proportions of patients who could be expected to benefit with each of our antibiotic regimens. Individuals vary in their response: thus some who fail to benefit from penicillin with streptomycin improve with high doses of ampicillin (Pines, 1964). In patients with renal impairment or in those over the age of 70 vestibular toxicity from streptomycin is so frequent that ampicillin or lymecycline is preferable, little difference in side-effects being found between these latter.

Elmes et al. (1965) found that ampicillin gave little advantage over placebo treatment in patients with acute exacerbations of bronchitis. The results of our pilot trial suggest that, on the contrary, it would be unethical not to give antibiotics when such patients are severely ill. Our patients may have had more severe and resistant illnesses. The difference may also reflect the superiority of penicillin with streptomycin to ampicillin. The higher and prolonged dosage of ampicillin we gave seemed more effective than that given by Elmes et al., and certainly better than placebo treatment in the pilot trial. When patients are not so ill chemotherapy may be less beneficialwe are investigating this.

We conclude that penicillin in high doses together with streptomycin is the antibiotic regimen of choice in the management of severe and acute purulent exacerbations of chronic bronchitis, both in ameliorating the infection and in preventing relapse later.

\section{Summary}

Treatment was given to 186 patients with moderate or severe acute exacerbations of chronic bronchitis, the antibiotic regimen being selected at random from penicillin with streptomycin, lyme- cycline (a better-tolerated derivative of tetracycline), or ampicillin, all in high dosage. The clinical results were "blindly" assessed and relevant ventilatory and laboratory data obtained. Penicillin with streptomycin was superior both in immediate results and during the follow-up period of up to one month, significantly so in several respects. Lymecycline and ampicillin were more or less equal to each other.

A pilot trial compared penicillin with streptomycin to a placebo ; unequivocal advantages were shown for those patients given chemotherapy.

We gratefully acknowledge the nursing and secretarial staff of Ware Park Hospital for their help; Dr. W. D. Linsell and the staff of the Pathology Laboratory of the Hertford County and Herts and Essex Hospitals for the laboratory estimations; Dr. J. R. May, Brompton Hospital, for the bacteriological results ; Dr. O. P. Robinson, Beechams Research Laboratories, and Carlo Erba (U.K.) Ltd., for supplies of ampicillin (Penbritin) and lymecycline (Tetralysal) respectively, and for grants towards expenses; Professor J. W. Crofton, University of Edinburgh, for criticism; and the physicians who sent us patients under their care.

\section{REFERENCES}

Elmes, P. C., et al. (1965). Brit. med. 7., 2, 904.

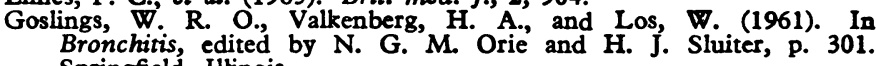
Springfield, Illinois.

Hafez, F. F., Stewart, S. M., and Burnet, M. E. (1965). Thorax, 20, 219.

Johnston, R. N. (1963). In Symposium on Chronic Respiratory Disorders, p. 76. Royal College of Physicians of Edinburgh.

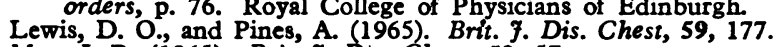

May, J. R. (1965). Brit. F. Dis. Chest, 59 57.

May, J. R., and Delves, D. M. (1964). Thorax, 19, 298.

Medical Research Council (1965). Lancet, 1, 775.

Mulder, J., Goslings, W. R. O., van der Plas, M. C., and Lopes Cardozo, P. (1952). Acta med. scand., 143, 32.

Pines, A. (1964). Lancet, 2, 445.

Pines, A., Plucinski, K., Greenfield, J. S. B., and Mitchell, R. C. (1964). Brit. med. 7., 2, 1495.

Scadding, J. G. (1966). Brit. med. F., 1, 1281.

Stuart-Harris, C. H. (1966). Prescrib. Ұ., 6, 54

Turk, D. C., and May, J. R. (1967). Haemophilus Influenzae, p. 73. London.

Wade, O. L. (1967a). Brit. med. 7., 3, 235.

Wade, O. L. (1967b). Postgrad. med.' F., March Suppl., 43, 25.

Zinnemann, K. (1960). Ergebn. Mikrobiol., 33, 307.

\title{
Involuntary Movements in Multiple Sclerosis
}

\author{
N. B. S. SARKARI,* M.D., B.SC., M.R.C.P.ED., M.R.C.P.GLASG.
}

Brit. med. F., 1968, 2, 738-740

Involuntary movements other than tremor, facial myokymia, and flexor spasms are so rarely recognized as a clinical manifestation of multiple sclerosis that no mention of chorea, athetosis, and Parkinsonism in this disease has been discovered in the British literature. Mouren et al. (1966) described one fatal case of hemiballismus due to multiple sclerosis and reviewed five cases from the literature. Four cases of athetosis with lesions of the spinal cord were reported by Balestrieri (1955), one of them being due to multiple sclerosis. Matthews (1958) described four cases showing tonic seizures and suggested that they might represent a central form of tetany. Lance (1963) suggested that these seizures might result from a temporary release of basal ganglia and reticular postural mechanism from cortical control. In view of the rarity of these features it would seem justifiable to describe the cases of three patients clinically suffering from multiple sclerosis in

* Midland Centre for Neurosurgery and Neurology, Smethwick, Warley,
Worcs. whom chorea or choreo-athetosis developed during the course of their illness.

\section{Case 1}

The patient was a woman aged 25. Five weeks before admission to hospital on 19 November 1967 she noticed weakness of the right side of the body on rising in the morning, with difficulty in walking and finding the correct words when trying to speak. She would also repeat the same words several times. On examination she had dysphasia, a right hemiplegia, and hypoalgesia of the right side of the body. After a few days during which the weakness increased she began to improve, and in the next two weeks the power returned to the right side. However, she then developed involuntary movements of the right arm and leg. There was no history of headaches, visual disturbance, or fits; she had never had rheumatic fever; she had not been using oral contraceptives; and there was no family history of tremor, involuntary movement, or mental disturbance.

On admission she was euphoric and showed a marked dysarthria but no dysphasia. Both discs were very pale. There was marked 
chorea, affecting the right arm and leg, both sides of the face, and the tongue. On exercising one limb obvious associated movements occurred in the affected as well as other parts of the body. Power in the limbs was normal, but all reflexes were exaggerated and both plantar reflexes were extensor. The gait was typical of chorea. The heart was normal, blood pressure $120 / 70$, and nothing abnormal was found in any of the other systems.

Investigations.-Full blood count was normal. E.S.R. was 21 $\mathrm{mm}$. in one hour. Urea and electrolytes were within normal limits. A throat swab produced a light growth of the usual flora and the antistreptolysin titre was 50 Todd units. Examination of the cerebrospinal fluid on 21 November showed no cells; protein $37 \mathrm{mg} . /$ $100 \mathrm{ml}$.; Lange 5532100000 ; negative W.R. C.S.F. protein electrophoresis showed a gammaglobulin of $14 \mathrm{mg}$., which is equal to $37.8 \%$ of total C.S.F. protein. A week later the C.S.F. showed no cells, protein $69 \mathrm{mg}$., Lange 5554210000 , negative W.R., and a gammaglobulin of $28.3 \mathrm{mg}$., equivalent to $40.8 \%$ of total protein. Electroencephalography produced a normal record with equal rate and amplitude of alpha activity on both sides, Radiological investigations, which included straight $x$-ray films of chest and skull and a left carotid arteriogram, were normal.

The diagnosis of multiple sclerosis in an active phase seemed the most likely possibility, and the patient was treated with corticotrophin on the following regimen: 80 units daily for six days, 60 units daily for three days, 40 units daily for three days, and then 20 units daily for two weeks. She improved considerably as regards involuntary movements within three days of starting corticotrophin. After discharge from hospital she was reviewed twice at intervals of two weeks. She was then absolutely symptomfree, the only noticeable signs on examination being increased tendon reflexes and a right extensor plantar response.

\section{Case 2}

The patient was a woman aged 54. About 19 to 20 years previously she had had an acute episode of unsteadiness, which improved in a few weeks ; but she had always been afraid of heights and since that time had had a tendency to fall. For a few months before admission in December 1967 the unsteadiness became worse and she could not maintain her balance even while standing. Her speech became slurred and she developed restlessness of the arms. Memory and intelligence were noted to be getting poor. There was no history of double vision, but she had had incontinence of urine at odd times.

On examination she was of thin build, with dorsal kyphosis and light pigmentation of the body. Higher cerebral functions showed early dementia. Speech was normal. The fundi and fields were normal. She had nystagmus on looking to the left. She was deaf in both ears, which had perforated drums of long standing. There was a mild intention tremor of the hands, and choreo-athetoid movements of the upper limbs were seen, affecting mainly the distal parts. No defect in motor power and no position or vibration sensory loss was demonstrated. There was marked ataxia of the legs. All tendon reflexes were exaggerated and the plantar responses were abnormal. The blood pressure was $110 / 80$ and other systems were normal.

Investigations.-Full blood count was normal. Blood W.R. was negative. C.S.F. examination showed normal pressure, no cells, protein $53 \mathrm{mg} . / 100 \mathrm{ml}$., Lange 5554321000 , and $\mathbb{W} . R$. negative C.S.F. protein electrophoresis showed a gammaglobulin of 15.8 mg., which is $32 \%$ of the total protein. The C.S.F. examination was repeated three weeks later and showed: cells 1 , protein $33 \mathrm{mg} . /$ $100 \mathrm{ml}$, Lange 5554321100, and W.R. negative. Electroencephalogram produced runs of slow waves on both sides. Straight $x$-ray films of chest and skull were within normal limits, The air encephalogram showed features suggestive of bilateral cortical atrophy.

This patient showed considerable spontaneous improvement. The nystagmus, intention tremor, and choreo-athetoid movements practically disappeared within two weeks while the investigations were being completed. She started walking without ataxia, and when seen two weeks after discharge the only signs were early dementia and exaggerated tendon reflexes with abnormal plantar responses.

\section{Case 3}

A man aged 25 was admitted to hospital as an urgent case on 31 October 1964. Ten days before admission he developed weak- ness of the left leg, followed next day by weakness of the left arm. Within the next 48 hours his face became weak on the left side and he developed retention of urine. He was confused and extremely restless. There was no history of headache, vomiting, or visual disturbance and no fever.

On examination he was florid, dehydrated, extremely restless, and constantly moving in a confused fashion. There was appreciable dysarthria. The fundi and fields were normal. Gross nystagmus was noted during horizontal movement of the eyes, Left hemianopia and left facial weakness of upper motor neurone type were present. There was severe weakness of the left arm and leg with spasticity. The right side showed ataxia and intention tremor. The tendon reflexes were exaggerated, left more than right, and both plantars were extensor. There was no neck stiffness and Kernig's sign was negative. The blood pressure was $130 / 84$ and other systems were normal.

Investigations.-Full blood count was normal. E.S.R. was 17 mm. in one hour, Blood W.R. was negative. The C.S.F. was at normal pressure and contained $10 \mathrm{cells} / \mathrm{cu}$. mm., all lymphocytes, protein $33 \mathrm{mg} . / 100 \mathrm{ml}$., Lange 4432100000, and W.R. negative. Electroencephalogram showed generalized slow activity, more on the right side. Radiological investigations, which included straight $x$-ray films of chest and skull and bilateral carotid angiography, were within normal limits, but pneumoencephalography showed slight dilatation of the lateral ventricles without any obstruction or displacement of the aqueduct or fourth ventricle.

Despite the unusual features, multiple sclerosis seemed to be the most likely diagnosis. He was treated with corticotrophin 80 units daily for 10 days, 60 units daily for four days, and then 40 units daily for 10 days, followed by prednisolone $5 \mathrm{mg}$. twice a day for two weeks and then $2.5 \mathrm{mg}$, twice a day for a further two weeks. Within a few days of starting corticotrophin there was a distinct improvement, particularly in his mental state and bladder function. A month later, though fairly well and up and about, he complained of twisting uncontrollable movements of the right hand and arm. There were also signs of mild left hemiparesis with mild spasticity but no nystagmus or ataxia. Over the next three months the athetosis improved spontaneously and he was able to undertake light work. He was followed up intermittently over the next two years, was married in March 1967, and when seen in July was symptom-free and examination showed only a very mild weakness of the left side with brisk tendon reflexes.

\section{Discussion}

In describing unusual features in multiple sclerosis one is always faced with the problem of diagnosis, which in the majority of cases is a presumptive one, as post-mortem proof is so rarely obtained. There are, however, certain pointers to diagnosis, which were present in each of these cases. They showed an acute illness and in Case 2 there was a story of relapse and remission. They also showed signs of multiple lesions in the nervous system. The findings in the cerebrospinal fluid-a strongly paretic Lange curve with a negative Wassermann reaction, and high percentage of gammaglobulin on electrophoresis of the fluid-were characteristic of the disease. Cases 1 and 3 showed immediate and good response to corticotrophin, and investigations directed towards other relevant structural lesions were negative.

It is rather surprising that such involuntary movements do not happen more often when it is considered how widespread are the lesions in multiple sclerosis. This is also true for dysphasic speech disturbances and hemianopia, which are well documented but extremely rare. It would seem reasonable to consider that the corpus striatum is involved in these cases, and it is worth noting that these were acute and diffuse processes. This corresponds well with the case of hemiballismus due to multiple sclerosis described by Mouren et al. (1966), where the corpus striatum and subthalamic nuclei were involved along with other cerebral structures.

Experience of these cases shows that when a young patient presents with involuntary movements it is justifiable to consider the possibility of multiple sclerosis in the differential diagnosis. 


\section{Summary}

Three cases of multiple sclerosis are reported, all of which developed chorea, choreo-athetosis, or athetosis during the course of their illness. The diagnoses were based on the association of diffuse and disseminated neurological lesions, a history of remission and relapse, a strongly paretic Lange curve in the C.S.F. with a negative Wassermann reaction, together with marked increase in the gammaglobulin fraction. Two cases responded well to corticotrophin and one improved spontaneously. Follow-up showed satisfactory remission of the whole clinical picture and of voluntary movements in particular.
I am grateful to Dr. J. MacDonald Holmes for permission to report his cases. I am indebted to Dr. E. R. Bickerstaff for permission to publish the case under his care and for his criticism and guidance in preparing this paper. I am thankful to Miss G. M. Griffiths and Miss S. Ray for their help at various stages.

\section{REFERENCES}

Balestrieri, A. (1955). G. psichiat. Neuropat., 83, 597.

Lance, J. W. (1963). F. Neurol. Neurosurg. Psychiat., 26, 51. Matthews, W. B. (1958). Brain, 81, 193.

Mouren, P., Tatossian, A., Toga, M., Poinso, Y., and Blumen, G. (1966). Encéphale, 55, 212.

\title{
Verapamil in Angina: a Double-blind Trial
}

\author{
D. N. PHEAR,* M.A., M.D., M.R.C.P., M.R.A.C.P.
}

Angina is a common and sometimes disabling symptom. So far, only two drugs of proved value are available for the symptomatic relief of angina. These are glyceryl trinitrate, effective but short-acting, and propranolol, which may precipitate heart failure by blocking the powerful $\beta$-adrenergic stimulation on which a damaged heart depends (Gillam and Prichard, 1965). Other effective drugs with prolonged action would be valuable, and verapamil has been reported to improve anginal pain. Verapamil is probably not a $\beta$-adrenergic blocking agent (Bateman, 1967), but has a non-specific depressant action on the myocardium (Fitzgerald and Barrett, 1967).

A double-blind trial of verapamil in 20 outpatients with angina is here reported.

\section{Method of Trial}

Twenty outpatients with angina took part in the trial ; there were 13 men and 7 women, with mean age of 58.1 years. All had troublesome angina requiring from 1 to 10 glyceryl trinitrate tablets daily (mean 3.7 tablets) for relief, even in a limited life. The electrocardiogram was normal in seven patients and showed a pattern of old myocardial infarction in four, with minor ischaemic changes in the remaining nine. Ten patients also had anticoagulant treatment with phenindione throughout the trial.

Each patient received verapamil $80 \mathrm{mg}$. three times daily for two weeks and identical control tablets for a further fortnight. The treatment periods were arranged by a double-blind randomized scheme, so that 10 patients started on verapamil and 10 on control tablets. Patients were seen fortnightly and assessed without knowing which tablets were being taken. The frequency and severity of angina were estimated, together with the number of glyceryl trinitrate tablets required and the amount of activity possible.

\section{Results}

Four patients preferred verapamil to the control tablets, and three preferred the control tablets to verapamil. Only two patients showed great improvement during the trial and became

* Consultant Physician, St. Albans City Hospital and Queen Elizabeth II Hospital, Welwyn Garden City. free of angina; one of these was taking verapamil and one control tablets. Nine patients noticed no change in angina throughout both trial periods, three were improved during both verapamil and control periods, and one patient was worse in both periods, having been on propranolol before the trial.

No side-effects were reported with either verapamil or the control tablets. The sensitivity to phenindione of the 10 patients on this drug did not alter significantly throughout the trial.

\section{Discussion}

The present study shows no evidence of useful relief of angina by verapamil. This drug has been introduced as a mild blocker of the $\beta$-adrenergic receptors in heart muscle (Bateman, 1967). Verapamil, however, does not prevent the tachycardia produced by isoprenaline in man, nor does it reduce tachycardia after exercise in healthy volunteers as propranolol does (Fitzgerald and Barrett, 1967) ; and verapamil probably acts as a non-specific myocardial depressant, like procainamide or quinidine. Animal experiments have shown that verapamil increases coronary blood flow (Haas, 1964), but a number of drugs with this action have not proved useful for relief of angina (Phear, 1963). The reason, no doubt, is that the coronary blood flow is increased by verapamil in healthy subjects but not in patients with coronary artery disease (Luebs et al., 1966).

Uncontrolled clinical trials have shown good results in some 1,400 patients with angina; Hoffmann (1964), for instance, reported satisfactory or excellent relief of angina in $90 \%$ of 191 patients. It is well known, however, that only doubleblind trials are acceptable, because of the natural fluctuations of angina and the frequent placebo effects recorded with new treatments for angina. Two previous double-blind trials have been reported. Atterhög and Porjé (1966) showed that the performance of 13 men during an exercise test on a bicycle ergometer was improved by verapamil; and Neumann and Luisada (1966) compared verapamil with placebo in 30 residents of an old people's home, and found that the consumption of glyceryl trinitrate from their weekly allocation was less while on verapamil than in the control period. These patients were elderly, average age 80.4 years, and inactive; also, the average number of anginal attacks was 8.8 per week, but the average 